\title{
Efeitos na função pulmonar após utilização de surfactante pulmonar exógeno na síndrome do desconforto respiratório agudo na criança
}

\author{
W.B. de Carvalho, C.M.F. MÂngia \\ Disciplina de Pediatria Clínica da Universidade Federal de São Paulo - Escola Paulista de M edicina, São Paulo, SP.
}

\begin{abstract}
RESUMO - A síndrome do desconforto respiratório agudo (SDRA) é uma lesão pulmonar de causa multifatorial em que o sistema surfactante se apresenta alterado por causa da sua inativação e comprometimento da composição e metabolismo. A utilização do surfactante pulmonar exógeno é uma opção terapêutica que visa manter a estabilidade alveolar, propiciando, dessa forma, a meIhora da complacência pulmonar (aumentando a capacidade residual funcional), da oxigenação e da mecânica respiratória.

Os autores relatam o estudo realizado com a utilização de uma dose de surfactante pulmonar exógeno em dois pacientes pediátricos com SDRA submetidos a ventilação pulmonar mecânica.
\end{abstract}

\section{INTRODUÇÃO}

Os pacientes com síndrome do desconforto respiratório agudo (SDRA) ${ }^{1}$ têm comprometimento da função do surfactante semel hante ao que ocorre no desconforto respiratório do período neonatal em relação aos aspectos anatomopatológi cos e funcionais, tendo essa disfunção, na SDRA, causa multifatorial.

No período neonatal, a administração de surfactante pulmonar exógeno em recém-nascidos prematuros é, hoje, uma rotina. Em 1959, Avery e Nead observaram que os prematuros faleciam devido a um quadro de desconforto respiratório associado a deficiência de surfactante. Nos últimos anos, a utilização de surfactante exógeno nas unidades de terapia intensiva neonatais fez com que houvesse queda de até $50 \%$ na mortalidade dos recém-nascidos pré-termos.

A SDRA ${ }^{2}$, no paciente pediátrico, desenvolve-se secundariamente a uma agressão pulmonar aguda grave como, por exemplo, trauma, sepse, queimadura, acidente por submersão e inal ação de fumaça, levando a um comprometimento crítico da função respiratória caracterizado, clinicamente, por hipoxemia e redução da complacência pulmonar, e, no exame radiológico do tórax, observa-se infiltrado alvéolo intersticial difuso característico da síndrome. A fisiopatologia da doença envolve acúmulo de material proteináceo que causa, secunda-
Avaliam os pacientes com gasometria arterial e venosa pré e pós-utilização de surfactante, sendo observada melhora na oxigenação, redução do shunt intrapulmonar, melhora da ventilação imediatamente após a instilação da preparação na cânula orotraqueal e retorno à situação pré-administração após 240 minutos, no caso 1, e após 120 minutos, no caso 2 . Concluem que ainda são necessários vários estudos clínicos prospectivos e randomizados para avaliar, de forma eficaz, essa modalidade terapêutica na SDRA.

UNITERMOS: Síndrome do desconforto respiratório agudo. Surfactante. Lesão pulmonar aguda. Criança.

riamente, destruição ou mudança na composição dos componentes protéicos e lipídicos do sistema surfactante. Tem sido demonstrado, na literatura, que a razão dos componentes lipídicos do surfactante é anormal e tem sua função reduzida ${ }^{3}$. Encontra-se, também, uma correlação positiva entre o grau da disfunção do sistema surfactante e a gravidade da SDRA.

Os estudos clínicos com a utilização de surfactante na SDRA são limitados e a maioria dos estudos envol ve relato de casos. Existem apenas dois estudos prospectivos e randomizados que demonstram um benefício na utilização de surfactante pulmonar exógeno na SDRA. Weg ${ }^{4}$, estudando pacientes sépticos com SDRA, utilizou surfactante em aerossol e demonstrou melhora significativa na fração de shunt pulmonar, na complacência pulmonar estática e redução da mortalidade. Weidemann ${ }^{5}$ realizou um estudo prospectivo randomizado utilizando surfactante sintético via aerossol, obtendo mel hora importante da oxigenação e diminuição da mortalidade.

Este artigo descreve nossa experiência com o uso de surfactante pulmonar exógeno na SDRA da criança, relatando dois casos da unidade de terapia intensiva pediátrica do Hospital São Paulo da Universidade Federal de São Paulo internados em junho de 1994. N osso obj eti vo é demonstrar que há mel hora da oxigenação e queda da fração de "shunt 


\begin{tabular}{|c|c|c|c|c|c|c|c|c|}
\hline \multirow{3}{*}{ Gasometria pré-nitroprussiato* } & & $\mathrm{pH}$ & $\mathrm{PCO}_{2}$ & $\mathrm{PO}_{2}$ & BIC & $\mathrm{CO}_{2} \mathrm{~T}$ & BE & $\mathrm{SatO}_{2}$ \\
\hline & Arterial & 7,32 & 51,5 & 53,5 & 26,1 & 27,7 & 0 & 84,5 \\
\hline & Venosa & 7,29 & 61,8 & 39,9 & 29,5 & 31,4 & 2,3 & 68,4 \\
\hline \multirow[t]{2}{*}{ Gasometria pós-nitroprussiato } & Arterial & 7,37 & 35,1 & 74,3 & 20,1 & 21,2 & $-4,3$ & 94,2 \\
\hline & Venosa & 7,34 & 64,0 & 43,6 & 34,1 & 36,1 & 6,5 & 76,2 \\
\hline
\end{tabular}

\begin{tabular}{|c|c|c|c|c|c|c|c|c|c|c|}
\hline & & $\mathrm{pH}$ & $\mathrm{PCO}_{2}$ & $\mathrm{PO}_{2}$ & BIC & $\mathrm{CO}_{2} \mathrm{~T}$ & BE & Sat $\mathrm{O}_{2}$ & $\begin{array}{c}\text { Shunt } \\
\text { pulmonar }\end{array}$ & $\begin{array}{r}\text { Relação } \\
\mathrm{PaO}_{2} / \mathrm{FiO}_{2}\end{array}$ \\
\hline $\begin{array}{l}\text { Gasometria pré- } \\
\text { surfactante* }^{*}\end{array}$ & $\begin{array}{l}\text { Arterial } \\
\text { Venosa }\end{array}$ & $\begin{array}{l}7,36 \\
7,32\end{array}$ & $\begin{array}{l}48,2 \\
66,3\end{array}$ & $\begin{array}{l}91,5 \\
50,9\end{array}$ & $\begin{array}{l}26,5 \\
34,1\end{array}$ & $\begin{array}{l}28,3 \\
36,1\end{array}$ & $\begin{array}{l}1,3 \\
6,2\end{array}$ & $\begin{array}{l}96,5 \\
82,6\end{array}$ & 24,3 & 101,6 \\
\hline $\begin{array}{l}\text { Imediatamente } \\
\text { após surfactante }\end{array}$ & $\begin{array}{l}\text { Arterial } \\
\text { Venosa }\end{array}$ & $\begin{array}{l}7,30 \\
7,27\end{array}$ & $\begin{array}{l}43,0 \\
67,1\end{array}$ & $\begin{array}{r}109,3 \\
61,4\end{array}$ & $\begin{array}{l}20,8 \\
30,2\end{array}$ & $\begin{array}{l}22,2 \\
32,2\end{array}$ & $\begin{array}{r}-5,2 \\
1,3\end{array}$ & $\begin{array}{l}97,4 \\
87,2\end{array}$ & 23,7 & 121,4 \\
\hline Após 30min** & $\begin{array}{l}\text { Arterial } \\
\text { Venosa }\end{array}$ & $\begin{array}{l}7,37 \\
7,30\end{array}$ & $\begin{array}{l}50,2 \\
55,7\end{array}$ & $\begin{array}{l}46,3 \\
45,2\end{array}$ & $\begin{array}{l}28,7 \\
27,2\end{array}$ & $\begin{array}{l}30,3 \\
28,9\end{array}$ & $\begin{array}{r}2,7 \\
-0,1\end{array}$ & $\begin{array}{l}80,6 \\
76,0\end{array}$ & 15,9 & 77,1 \\
\hline Após $60 \mathrm{~min}^{* *}$ & $\begin{array}{l}\text { Arterial } \\
\text { Venosa }\end{array}$ & $\begin{array}{l}7,37 \\
7,31\end{array}$ & $\begin{array}{l}30,9 \\
53,2\end{array}$ & $\begin{array}{l}71,3 \\
39,4\end{array}$ & $\begin{array}{l}17,9 \\
26,7\end{array}$ & $\begin{array}{l}18,8 \\
28,3\end{array}$ & $\begin{array}{r}-6,2 \\
0,8\end{array}$ & $\begin{array}{l}93,6 \\
69\end{array}$ & 15,7 & 116,8 \\
\hline Após $120 \mathrm{~min}^{* *}$ & $\begin{array}{l}\text { Arterial } \\
\text { Venosa }\end{array}$ & $\begin{array}{l}7,40 \\
7,36\end{array}$ & $\begin{array}{l}32,3 \\
53,4\end{array}$ & $\begin{array}{l}74,7 \\
44,0\end{array}$ & $\begin{array}{l}20,1 \\
29,9\end{array}$ & $\begin{array}{l}21 \\
31,5\end{array}$ & $\begin{array}{r}-3,4 \\
3,4\end{array}$ & $\begin{array}{l}94,8 \\
77,8\end{array}$ & 15,5 & 124,5 \\
\hline Após $240 \mathrm{~min}$ *** & $\begin{array}{l}\text { Arterial } \\
\text { Venosa }\end{array}$ & $\begin{array}{l}7,36 \\
7,33\end{array}$ & $\begin{array}{l}56,0 \\
65,8\end{array}$ & $\begin{array}{l}42,2 \\
30,1\end{array}$ & $\begin{array}{l}31,7 \\
34,3\end{array}$ & $\begin{array}{l}33,4 \\
36,4\end{array}$ & $\begin{array}{l}5,0 \\
5,6\end{array}$ & $\begin{array}{l}76,0 \\
52,7\end{array}$ & 25,5 & 47,4 \\
\hline
\end{tabular}

pulmonar" refletindo a potencialidade clínica dessa modalidade terapêutica

\section{Caso 1}

Paciente com 40 dias de vida, procurou o hospital com quadro de tosse produtiva, cansaço, vômitos e cianose. No pronto socorro, começou a apresentar episódios repetidos de apnéia e bradicardia, sendo internada na UTI pediátrica. Ao exame clínico: descorado, com episódios de apnéia, bradicardia e cianose. Presença de estertores crepitantes em hemitórax direito e sopro sistólico em foco pulmonar $+1 /+6$. Fígado a $2 \mathrm{~cm}$ do rebordo costal direito, na linha hemiclavicular; boa perfusão periférica.

Levantadas as seguintes hipóteses diagnósticas: apnéia de etiologia a esclarecer e pneumonia aspirativa com atel ectasia.

Desde o 2ㅇ dia de internação, teve início quadro de broncoespasmo, diminuição de pulsos periféricos e crises de cianose. Introduzidas dobutamina, $5 \mathrm{mcg} / \mathrm{kg} / \mathrm{min}$; terbutalina, 0,4mg/kg/hora, e expansões fluídicas e correção do nível de hemoglobina $(\mathrm{Hb}=6,4)$.

No 4 dia de internação, houve piora clínica importante com taquicardia, estertoração pulmo- nar crepitante, perfusão lentificada associada a sinais de baixo débito, com infiltrado pulmonar intersticial bilateral, comparativamente pior que o anterior. Introduzidas clindamicina e ceftriaxona e aumentada a dobutamina para $10 / \mathrm{mcg} / \mathrm{kg} /$ min. Levantada a hipótese de SDRA (rel ação $\mathrm{PaO}_{2}$ ) $\mathrm{FiO}_{2}=199$ ).

No 6o dia, desenvolveu edema generalizado, crises de hipertensão pulmonar às manipulações (queda da saturação na oximetria de pulso, taquicardia, cianose e hipotensão arterial). Ao exame radiológico do tórax: condensação em hemitórax direito e base do hemitórax esquerdo e aspecto retículo nodular difuso com aerobroncograma. A plicado o escore de lesão pulmonar aguda ${ }^{6}=2,6$; relação $\mathrm{PaO}_{2} / \mathrm{FiO}_{2}=91$ e fração de shunt pulmonar (calculado) $=23 \%$.

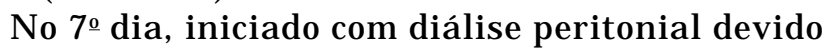
a SDRA e baixo débito cardíaco. A seguir ( $8^{\circ}$ dia), colocado no aparel ho de ventilação pulmonar mecânica Servo Siemens 900C utilizando-se a modalidade pressão controlada e fluxo desacelerante.

No 9o dia, iniciado com nitroprussiato de sódio devido às crises freqüentes de hipertensão pulmonar; em doses baixas com o objetivo de reduzir a 


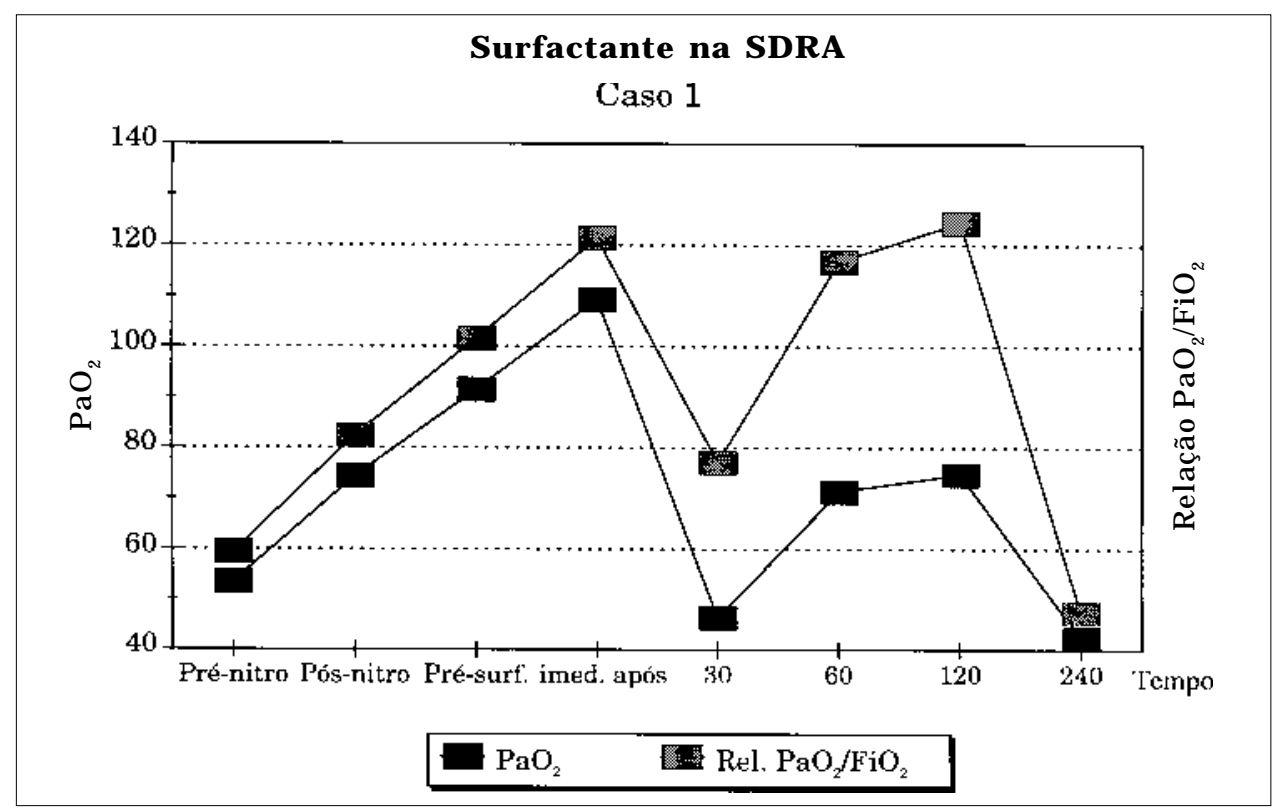

Fig. 1 - Caso 1. Surfactante na SDRA. Note o incremento da oxigenação após utilização de surfactante entre 60 e 120 minutos. A redução na $\mathrm{PaO}_{2}$ e da relação $\mathrm{PaO}_{2} / \mathrm{FiO}_{2}$ após 30 minutos da instilação de surfactante ocorreu devi do à redução inadvertida da $\mathrm{FiO}_{2}$ do equipamento de ventilação pulmonar mecâni ca de $90 \%$ para $60 \%$, resultando na hipóxia verificada na gasometria (fenômeno de "flip-flop").

\section{Fig. 2 - Caso \\ 1. Observe o padrão \\ radiológico pré-} surfactante.

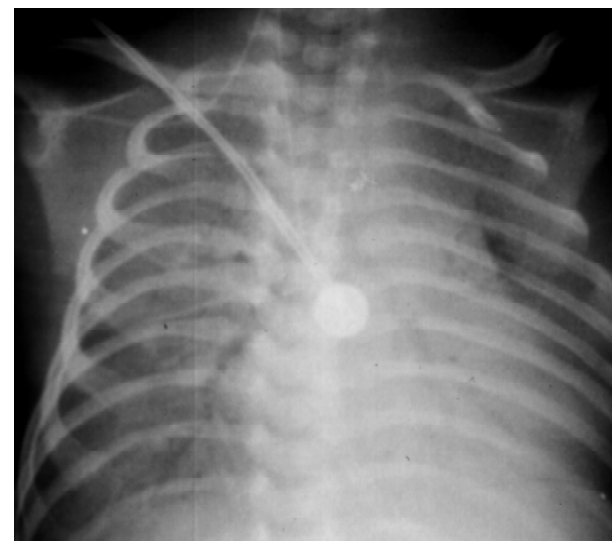

pressão do leito vascular pulmonar com um mínimo de repercussão sistêmica (tabela 1). A pressão arterial sistêmica foi monitorizada de forma invasiva pela artéria radial direita, evitando-se, desta forma, a hipotensão arterial. Após 12 horas do início do nitroprussiato de sódio, optamos por indicar a suplementação de surfactante pulmonar exógeno (Survanta ${ }^{\circledR}$ ), 100 $\mathrm{mg} / \mathrm{kg} / \mathrm{dose}$.

O equi pamento de ventilação pulmonar mecânica estava ajustado nos seguintes parâmetros: fração inspirada de oxigênio $\left(\mathrm{FiO}_{2}\right)=90 \%$, pressão inspiratória $(\mathrm{PIP})=58,5 \mathrm{~cm}$ de $\mathrm{H}_{2} \mathrm{O}$, pressão expiratória final positiva (PEEP) $=12 \mathrm{~cm}$ de $\mathrm{H}_{2} \mathrm{O}$, freqüência respiratória $(F R)=31$ respiraçốes por minuto (resp./min), volume corrente inspirado $(\mathrm{VCl})=53 \mathrm{~mL}$, volume corrente expirado $(\mathrm{VCE})=$

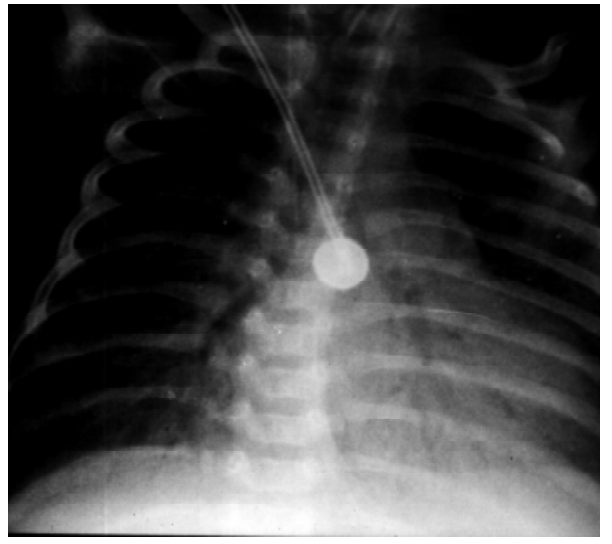

Fig. $\mathbf{3}$ - Caso

1. Padrão radiol ógico após 6 horas da administração do surfactante. Note a melhora da aeração pulmonar.

$58 \mathrm{~mL}$ e pressão média das vias aéreas (PMVA) $=$ $34,2 \mathrm{~cm}$ de $\mathrm{H}_{2} \mathrm{O}$ (tabela 2 e fig. 1).

O surfactante pulmonar exógeno foi instilado gota a gota, na cânula orotraqueal, em 15 minutos, através de intermediário neonatal próprio para esse fim, não sendo utilizada nenhuma outra manobra adicional (figs. 2 e 3).

A criança sobreviveu, mas permaneceu dependente de suporte ventilatório mecânico, evoluindo com displasia broncopulmonar, e, no 40 dia de internação, desenvolveu pneumotórax hipertensivo, com parada cardiorrespiratória subseqüente não-responsiva a manobras de reanimação.

\section{Caso 2}

Paciente com 2 meses e 8 dias, foi internado com 


\begin{tabular}{|c|c|c|c|c|c|c|c|c|c|c|}
\hline & & pH & $\mathrm{PCO}_{2}$ & $\mathrm{PO}_{2}$ & BIC & $\mathrm{CO}_{2} \mathrm{~T}$ & BE & Sat $\mathrm{O}_{2}$ & $\begin{array}{c}\text { Shunt } \\
\text { pulmonar }\end{array}$ & $\begin{array}{r}\text { Relação } \\
\mathrm{PaO}_{2} / \mathrm{FiO}_{2}\end{array}$ \\
\hline Pré-surfactante* & $\begin{array}{l}\text { Arterial } \\
\text { Venoso }\end{array}$ & $\begin{array}{l}7,42 \\
7,36\end{array}$ & $\begin{array}{l}39,1 \\
48,1\end{array}$ & $\begin{array}{l}53,6 \\
30,9\end{array}$ & $\begin{array}{l}25,1 \\
27,0\end{array}$ & $\begin{array}{l}26,3 \\
28,5\end{array}$ & $\begin{array}{l}0,8 \\
1,4\end{array}$ & $\begin{array}{l}88,0 \\
56,7\end{array}$ & 25,0 & 62,3 \\
\hline Imediata/e após** & $\begin{array}{l}\text { Arterial } \\
\text { Venoso }\end{array}$ & $\begin{array}{l}7,38 \\
7,29\end{array}$ & $\begin{array}{l}41,0 \\
56,0\end{array}$ & $\begin{array}{l}66,6 \\
33,4\end{array}$ & $\begin{array}{l}24,0 \\
26,0\end{array}$ & $\begin{array}{l}25,3 \\
27,7\end{array}$ & $\begin{array}{r}0,7 \\
-1,5\end{array}$ & $\begin{array}{l}92,4 \\
56,2\end{array}$ & 27,7 & 70 \\
\hline Após 30min & $\begin{array}{l}\text { Arterial } \\
\text { Venoso }\end{array}$ & $\begin{array}{l}7,45 \\
7,31\end{array}$ & $\begin{array}{l}33,9 \\
51,8\end{array}$ & $\begin{array}{l}57,7 \\
30,5\end{array}$ & $\begin{array}{l}23,4 \\
25,3\end{array}$ & $\begin{array}{l}24,5 \\
26,9\end{array}$ & $\begin{array}{r}0,3 \\
-0,8\end{array}$ & $\begin{array}{l}90,9 \\
51,7\end{array}$ & 28,6 & 64 \\
\hline Após 60min & $\begin{array}{l}\text { Arterial } \\
\text { Venoso }\end{array}$ & $\begin{array}{l}7,41 \\
7,31\end{array}$ & $\begin{array}{l}41,9 \\
54,3\end{array}$ & $\begin{array}{l}83,9 \\
31,7\end{array}$ & $\begin{array}{l}26,4 \\
26,9\end{array}$ & $\begin{array}{l}27,7 \\
28,5\end{array}$ & $\begin{array}{l}1,8 \\
0,5\end{array}$ & $\begin{array}{l}96,2 \\
84,6\end{array}$ & 26,8 & 88,4 \\
\hline Após $120 \mathrm{~min}^{* * *}$ & $\begin{array}{l}\text { Arterial } \\
\text { Venoso }\end{array}$ & $\begin{array}{l}7,43 \\
7,19\end{array}$ & $\begin{array}{l}43,7 \\
62,0\end{array}$ & $\begin{array}{l}52,4 \\
26,5\end{array}$ & $\begin{array}{l}28,5 \\
22,9\end{array}$ & $\begin{array}{l}29,8 \\
24,8\end{array}$ & $\begin{array}{r}3,7 \\
-5,3\end{array}$ & $\begin{array}{l}87,6 \\
34,9\end{array}$ & 28,3 & 55,1 \\
\hline
\end{tabular}

história de tosse, cansaço e diarréia. Clinicamente, apresentava-se taquidispnéico, febril e desidratado. Evoluiu com aci dose metabólica de difícil correção, piora do padrão respiratório, com respiração irregular, pausas respiratórias e má perfusão periférica. Admitida na UTI com hipótese diagnóstica de sepse e pneumonia intersticial, estando em mau estado geral, descorado, estertoração difusa bilateral, com drenagem torácica à esquerda apresentando fístula broncopleural.

No $4^{\circ}$ dia de internação, com melhora clínica e gasométrica, iniciou-se a retirada de ventilação pulmonar mecânica, sendo extubada no dia seguinte. Após 48 horas da extubação, desenvolveu picos febris, taquidispnéia, empiema à esquerda, hipotensão e hipoperfusão. O exame radiológico do tórax revel ou padrão alvéol o intersticial bilateral, dreno de tórax à esquerda bem posicionado e sem pneumotórax.

Com o quadro clínico e radiológico descrito, levantada hipótese diagnóstica de: 1) choque séptico; e 2) SDRA. Iniciou-se antibioticoterapia com vancomicina e ceftriaxona, por suspeita clínica de infecção nosocomial, reanimação fluídica e suporte inotrópico (dobutamina na dose inicial de $5 \mathrm{mcg} /$ $\mathrm{kg} / \mathrm{min}$ ). Instituída ventilação pulmonar mecânica no Servo Siemens $900 C$, com pressão controlada e fluxo desacelerante, objetivando-se a ventilação pulmonar com hipoxemia e hipercapnia permissiva. O equipamento foi ajustado nos seguintes parâmetros: $\mathrm{FiO}_{2}=85 \%$; $\mathrm{PIP}=40 \mathrm{~cm} \mathrm{H}_{2} \mathrm{O}$; PEEP $=$ $12 \mathrm{~cm} \mathrm{H}_{2} \mathrm{O}$; tempo inspiratório $\left(\mathrm{T}_{\text {insp }}\right)=0,75$ segundo; $\mathrm{VCl}^{2}=53 \mathrm{~mL}$; PMVA $=25 \mathrm{~cm} \mathrm{H} \mathrm{O}$.

Evoluiu, durante o 8o dia de internação, com piora ventilatória e escore para lesão pulmonar aguda acima de 2,6. A monitorização dos índices de oxigenação revelou fração de shunt intrapul- monar calculado de $25,5 \%$ e relação $\mathrm{PaO}_{2} / \mathrm{FiO}_{2}=$ 70,3 . Após 24 horas, indicada a utilização de surfactante pulmonar exógeno (Survanta ${ }^{\circledR}$ ), $100 \mathrm{mg} / \mathrm{kg} /$ dose, instilado gota a gota na cânula orotraqueal por intermediário neonatal, sem a utilização de manobras (tabela 3 e fig. 4).

Após 4 horas, a criança apresentou parada cardíaca devido a um pneumotórax hipertensivo bilateral, evoluindo para óbito .

\section{DISCUSSÃO}

O sistema surfactante é importante para manter a estabilidade alveolar e, conseqüentemente, a função pulmonar. As alterações desse sistema na SDRA são consideradas a principal causa de atelectasias e instabilidade alveol ar.

Sabe-se, por estudos em animais e em pacientes, que as alterações do sistema surfactante são secundárias a: 1) alteração no metabolismo pulmonar anormal do surfactante; 2 ) inativação al veolar pelas proteínas e debris (bactérias, debris celulares, fibrina, fluido do edema) presentes dentro do espaço aéreo; 3) presença de mediadores inflamatórios potentes, encontrados nos alvéolos, que podem ocasionar lesão di reta no sistema surfactante. Esses achados, compatíveis com a alteração funcional do sistema surfactante, associado a redução da concentração do surfactante, dá-nos a base teórica para utilização de suplementação de surfactante pulmonar exógeno na SDRA.

A melhora da oxigenação e da complacência pulmonar foi verificada em estudos com animais. Van Daal ${ }^{7}$ utilizou extrato lipídico de surfactante bovino em ratos com pneumonia viral por influenza A. Em outros estudos em ratos com pneumo- 


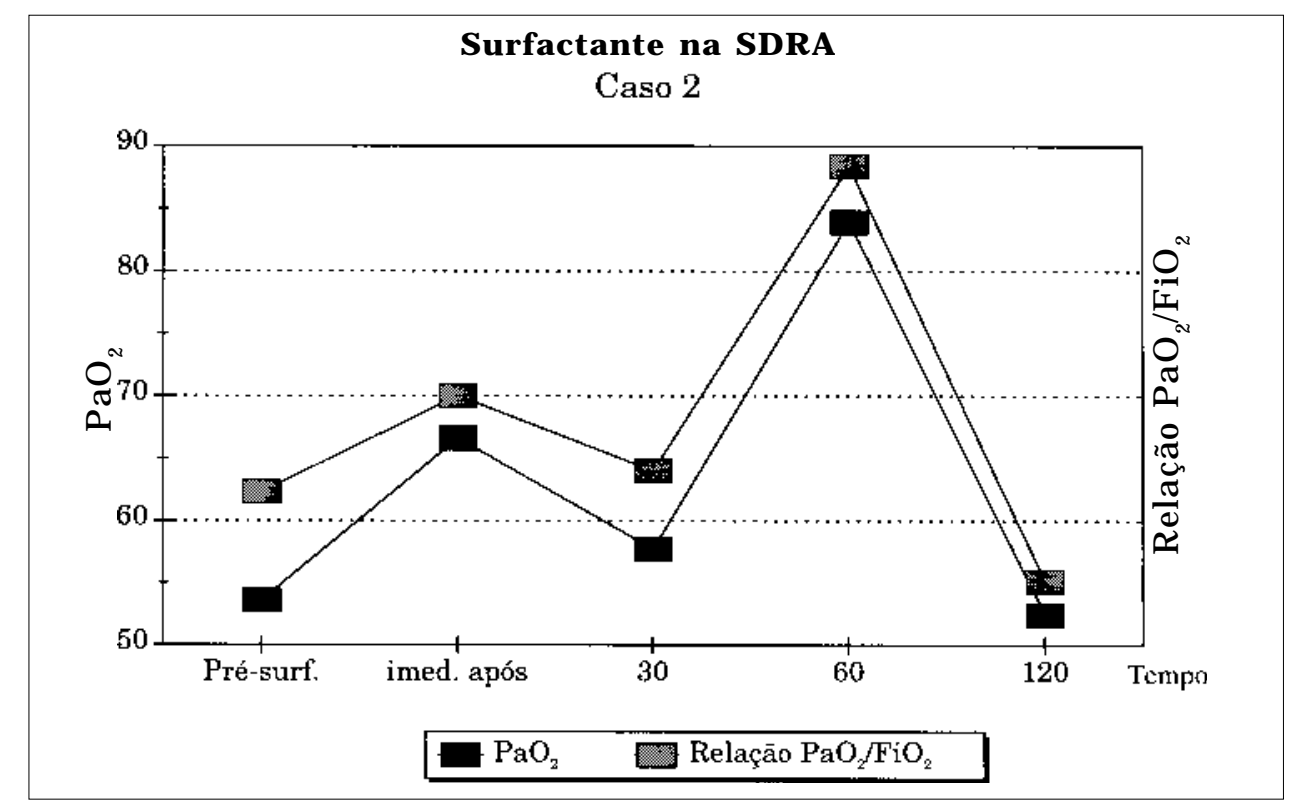

Fig. 4 - Note o incremento da oxigenação imediatamente após e após 60 mi nutos de administração do surfactante. A mel hora da oxigenação após 60 mi nutos pode ser explicada pelo caráter extremamente assimétrico da SDRA neste caso, suge rindo distribuição posterior do surfactante nessas áreas.

nia induzida por vírus Sendai ${ }^{8}$ e em pneumonia por Pneumocisti carinii ${ }^{9}$, os autores demonstraram melhora na função pulmonar e das trocas gasosas, com essa modalidade terapêutica.

E m crianças, Buheitel ${ }^{10}$ relatou melhora da troca gasosa após a utilização de surfactante em dois pacientes com SDRA devido a pneumonia, provavelmente viral. Harms ${ }^{11}$ utilizou surfactante bovino natural (Survanta ${ }^{\circledR}$ ) em duas crianças com SDRA devido a pneumonia por clamídia, e após 120 minutos da reposição de surfactante a relação $\mathrm{PaO}_{2} / \mathrm{FiO}_{2}$ aumentou de 52 para 84, em um caso, e no outro, de 35 para 94 . A pós 10 horas, foi instilada nova dose de surfactante, com a possibilidade de redução da ventilação pulmonar mecânica, e as crianças sobreviveram sem desenvolver doença pulmonar crônica.

Os relatos da literatura mostram que a terapia com surfactante exógeno produz melhora da expansibilidade secundária a aumento da complacência pulmonar, da capacidade residual funcional e redução do shunt intra-alveolar.

Estando o paciente em ventilação pulmonar mecânica é possível, devido a esses efeitos, reduzir a PIP, com redução do risco de barotrauma e volutrauma, diminuição da PEEP e redução da $\mathrm{FiO}_{2}$ com menos risco de toxicidade pelo oxigênio.

Quando comparamos os dois casos relatados, verificamos que houve melhora da $\mathrm{PaO}_{2}$, de 91,5 para 109,3 , e da relação $\mathrm{PaO}_{2} / \mathrm{FiO}_{2}$, de 101,6 para 121,4 , e queda na $\mathrm{PaCO}_{2}$, de 48,2 para 43,0, ime- diatamente após a instilação do surfactante, no caso 1 , sendo o mesmo observado no caso 2 , em que a $\mathrm{PaO}_{2}$ inicial se el evou de 53,6 para 66,6, havendo, também, aumento da relação $\mathrm{PaO}_{2} / \mathrm{FiO}_{2}$, de 62,3 para 70, imediatamente após a instilação, com a $\mathrm{PaCO}_{2}$ apresentando decréscimo após 30 minutos da instilação. No caso 1, houve retorno à situação de oxigenação inicial após 240 minutos e, no caso 2, após 120 minutos. Essa mel hora inicial da oxigenação foi , também, refletida pela diminui ção do escore de lesão pulmonar aguda, de 2,6 para 2,0, no caso 1 , e pela provável melhora da complacência pulmonar, que pode ser verificada pelo exame radiológico de tórax (caso 1). Comparando-se os dois casos, clinicamente, a gravidade da doença do caso 2 era maior que do caso 1 , podendo essa situação ser verificada pela $\mathrm{PaO}_{2}$ inicial dos dois casos.

A queda imediata da $\mathrm{PaCO}_{2}$, no caso 1 , e após 30 minutos, no caso 2 , pode ser reflexo da mel hora da oxigenação, que produziu diminuição na resistência da vasculatura pulmonar (vasoconstrição pulmonar hipóxica) e tornou mais eficaz a remoção de $\mathrm{CO}_{2}$.

O retorno à situação inicial prévia à administração de surfactante pode ser explicado pelo caráter heterogêneo da SDRA, com múltiplas áreas de atelectasia alveolar e bronquiolar, dificultando a distribuição homogênea do surfactante, além da sua inativação após algumas horas da administração.

A inativação do surfactante é descrita como secundária a fatores como a concentração aumentada 
de proteínas séricas específicas no espaço alveolar, quando comparada ao pool funcionante de surfactante endógeno, e quanto menor a concentração de surfactante endógeno mai or é o poder de ini bição. A presença de anticorpos monoclonais anti-surfactante é descrita, em estudos experimentais, como responsáveis pela inativação de surfactante bovino administrado de forma exógena ${ }^{12}$.

Dessa forma, necessitamos verificar qual o meIhor momento da administração de surfactante durante o curso da doença, uma vez que a gravidade da doença pode levar a disfunção importante do sistema surfactante e a insucesso terapêutico, pelas razões já descritas.

As técnicas atuais de administração do surfactante incluem instilação por meio de "bolos" e aerossol. Pela característica heterogênea da doença, alguns autores postulam o uso via aerossol. Outros, no entanto, acreditam que a associação das duas técni cas resul taria em melhor resposta nos pacientes com SDRA. Assim, o modo ótimo de admi nistração de surfactante na SDRA ainda é objeto de dúvida.

O tipo de preparação do surfactante a ser administrado também é objeto de investigação, já que as diferentes preparações são mais sensíveis a inativação por várias proteínas, entretanto em graus diferentes. Sabe-se, por exemplo, que preparações lipídicas sintéticas são mais sensíveis a inativação protéica quando comparadas com surfactante natural ou com extrato de surfactante natural. A adição de surfactante associado a proteínas, nas várias preparações lipídicas de surfactante, aumentaria a resistência dessas preparações à inibição pelas proteínas plasmáticas.

Concluímos que ainda são necessários vários estudos clínicos prospectivos, randomizados e ensaios multiinstitucionais de administração do surfactante exógeno em crianças com insuficiência respiratória aguda, já que irão proporcionar dados adicionais com respeito ao uso do surfactante exógeno nas crianças com SDRA.

\section{SUMMARY}

\section{Effects in the pulmonary function before single dose of exogenous pulmonary surfactant in chil- dren with acute respiratory distress syndrome (ARDS)}

The Acute Respiratory Distress Syndrome (ARDS) is a pulmonary lesion of multifactorial cause in which the surfactant system is altered owing to inactivation and impairment of compositi on and metabolism. The use of exogenous pulmonary surfactant is a therapeutic option with the objective to maintain alveolar stability thus improving the pulmonary compliance (increasing the residual functional capacity), oxygenation and ventilatory mechanics.

A study carried out on two pediatric patients with ARDS submitted to mechanic pulmonary ventilation, applying a single dose of exogenous pulmonary surfactant is described. The patients were evaluated using arterial and venous gasometry before and after the use of surfactant, observing increment in oxygenation, reduction of shunt fraction, improvement in ventilation immediately after exogenous pulmonary surfactant instillation and return to the previous situation after 240 minutes in case 1 and 120 minutes in case 2 . More prospective clinical and randomized studies are needed to effectivel y evaluate this therapeutic modality. [Rev Ass Med Brasil 1997; 43(2): 145-50]

KEY WORDS: Acute respiratory distress syndrome. Surfactant. Acute lung injury. Child. Critical illness therapy.

\section{REFERÊ NCIAS BIBLIOGRÁFICAS}

1. Lewis FJ, J obe AH. Surfactant and the adult respiratory distress syndrome. Am Rev Respir Dis 1993; 147: 218-33.

2. Peres-Benavides F, Riff E, Franks C. Adult respiratory distress syndrome and artificial surfactant replacement in the pediatric patient. Ped Emerg Care 1995; 11(1): 153-5.

3. Kresch MJ , Winnie HL, Thrall RS. Surfactant replacement therapy. Thorax 1996; 51: 1.137-54.

4. Weg J, Reines H, Balk R et al. Safety and efficacy of an aerosolized surfactant in human sepsis induced ARDS. Chest 1991; 100: 137.

5. Weidemann $H$, Baughman $R$, deBoisblanc $B$ et al. A multicentered trial in human sepsis induced ARDS of an aerosolized synthetic surfactant. Am Rev Respir Dis 1992; 145: A184.

6. Murray J F, Matthay MA, Luce J M et al. An expanded definition of adult respiratory distress syndrome. Am Rev Respir Dis 1988; 138: 720-23.

7. van Daal GJ , Bos J A, Eijking EP et al. Surfactant replacement therapy improves pulmonary mechanics in end-stageinfluenza A pneumonia in mice. Am Rev Respir Dis 1992; 145: 859-63.

8. van Daal GJ , So KL, Gommers D et al. Intratracheal surfactant administration restores gas exchange in experimental adult respiratory distress syndrome associated with viral pneumonia. Anesth Analg 1991; 72(5): 589-95.

9. Eijking EP, van Daal GJ , Tenbrinck et al. Improvement of pulmonary gás exchange after surfactant replacement in rats with Pneumocystis carinii pneumonia. Adv Exp Med Biol 1992; 316: 293-8.

10. Buheitel G, Scharf J, Harms D. Erfahrungen mit der Surfactanttherapie des adulten Atemnotsyndroms (ARDS). Monatsschr Kinderheilkd 1992; 140(9): 629-32.

11. Harms K, Herting E. Successful surfactant replacement therapy in two infants with ARDS dueto chlamydial. Respiration 1994; 61(6): 348-52.

12. Eijking EP, Strayer DS, van Daal GJ et al. In vivo and in vitro inativation of bovine surfactant by an anti-surfactant monoclonal antibody. Eur Respir J 1991; 4(10): 1.245-50. 